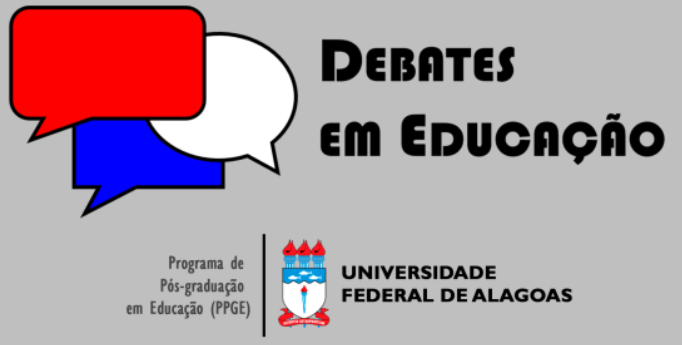

ISSN Eletrônico 2175-6600

Vol. 12 | Número Especial 2 | 2020

Fernanda do Santos Paulo

(9) iD

Universidade do Oeste de Santa Catarina (UNOESC)

fernanda.paulo@unoesc.edu.br

Mônica Tessaro

9 iD

Universidade do Oeste de Santa Catarina (UNOESC) m tessaro@unochapeco.edu.br

\section{SEMELHANÇAS E DIFERENÇAS ENTRE AS CONCEPÇÕES DE EDUCAÇÃO SOCIAL, EDUCAÇÃO POPULAR E EDUCAÇÃO NÃO ESCOLAR}

\section{RESUMO}

O texto trata das diferentes concepções e compreensões acerca da educação social, da educação popular e da educação não escolar. A partir de uma pesquisa bibliográfica, considera as particularidades, aproximações e distanciamentos teóricos e epistemológicos que se configuram no exercício da compreensão e uso desses termos nos múltiplos contextos educativos. $\bigcirc$ estudo revelou, no caso brasileiro, a presença de uma multidimensionalidade na compreensão desses três conceitos. $\bigcirc$ entendimento dessas concepções assume duas dimensões: crítica e pós-crítica. $\mathrm{Na}$ primeira, a educação popular não é sinônimo de educação não escolar e, ainda, não é o mesmo que educação social. Na segunda, privilegia-se diferentes referenciais para justificar uma educação social brasileira. Não se verificou um conceito explícito de educação social no Brasil, mas há semelhanças com o que conhecemos como educação popular

Palavras-chave: Contextos de educação. Educação Popular. Educação Social. Pedagogia Social.

\section{SIMILARITIES AND DIFFERENCES BETWEEN THE CONCEPTIONS OF SOCIAL EDUCATION, POPULAR EDUCATION AND NON-SCHOOL EDUCATION}

\begin{abstract}
The text deals with different conceptions and understandings about social education, popular education and non-school education. Based on a bibliographical research, it considers the particularities, approximations and theoretical and epistemological distancing that are configured in the exercise of understanding and using of these terms in the multiple educational contexts. The study revealed, in the Brazilian case, the presence of a multidimensionality in the understanding of these three concepts. The understanding of these conceptions assumes two dimensions: critical and post-critical. In the first, Popular Education is not synonymous with non-school education and is not the same as social education. In the second, different references are privileged to justify a Brazilian social education. There was no explicit concept of social education in Brazil, but there are similarities with what we know as popular education.
\end{abstract}

Keywords: Education Contexts. Popular Education. Social Education. Social Pedagogy.

Submetido em: $x x / x x / 20 x x$

Aceito em: $x x / x x / 20 x x$

Publicado em: $x x / 12 / 2020$

do http://dx.doi.org/ 10.28998/2 175-6600.2020v I 2nEsp2p76-97 


\section{INTRODUÇÃO}

O presente texto encontra-se ancorado no método hermenêutico crítico utilizado por Paulo Freire (1987, 2008), e interpreta, por meio de uma pesquisa bibliográfica, o uso das diferentes concepções e compreensões acerca da educação social, da educação popular e da educação não escolar. A hermenêutica crítica contribui para uma reflexão problematizadora, exigindo a dimensão histórica como elemento de leitura e compreensão do uso desses vocábulos, pois, nessa visão, a teoria é fruto do trabalho de intelectuais resultante das relações sócio históricas da/na construção de fenômenos interpretativos, os quais são originários de práticas sociais concretas.

Partindo desse entendimento, a compreensão histórica, intencional e política desses conceitos nos ajudará a interpretar e a fazer a leitura do mundo acadêmico, produtor de conhecimento, (re) significando e desvelando as compreensões sobre educação, utilizando novas linguagens em tempos e espaços marcados entre o passado, o presente e o que se deseja constituir como teorias da educação na contemporaneidade. Conforme Freire (2008), são homens e mulheres que significam as suas vivências (experiência existencial), a partir do que compreendem delas, e essa compreensão, quando ocorre, dá-se na relação mundo-sujeito-mundo. Por isso, a interpretação parte da "leitura do mundo que antecede a leitura da palavra" (FREIRE, 2008, p. 15).

Por esse caminho, examinaremos as particularidades, aproximações e distanciamentos teóricos e epistemológicos que se configuram no exercício da compreensão e uso desses termos nos múltiplos contextos educativos. Para isso, faremos o exercício, mesmo que breve, de identificar os sentidos e significados do uso do termo 'educação social' no contexto da educação brasileira, principalmente, nos últimos anos da década passada.

No Brasil, há grupos de pesquisadores que, influenciados pela educação europeia, sobretudo da Espanha e Alemanha, vêm produzindo pesquisas sobre educação social. Autores como Joham Heinrich Pestalozzi, Paul Gerald Natorp, Hermann Nohl, Claudio Volpi, Lourenzo Luzuriaga', José Antonio Caride Gómez, José Maria Quintana Cabanas, Violeta Nuñez e José Ortega Esteban, são autores referência de pesquisadores brasileiros. Interessante que, em alguns casos, usa-se a denominação educação social/pedagogia social, ou, separadamente, educação social como prática, e a pedagogia social como teoria. Em outros casos, educação social como sinônimo de educação não formal.

Em São Paulo, com o professor Roberto da Silva, emergem os primeiros debates sobre educação social. Inicialmente, com um curso de especialização; mais tarde, com a constituição do Programa de

\footnotetext{
' É um dos autores que faz referência à escola nova e à pedagogia como ato político (LUZURIAGA, 1983). Publicou um livro denominado: Pedagogia social e política, no ano de 1954. É um autor importante para a compreensão da concepção de pedagogia a partir da história da educação.
} 
Mestrado em Educação da Universidade Estadual de São Paulo (RIBAS, 20।4). Foi na primeira década dos anos 2000 que, no Brasil constituiu-se uma comunidade científica entre pesquisadores nacionais ${ }^{2}$ e internacionais ${ }^{3}$, todos mediados pelas fontes da pedagogia social, cuja presença de Paulo Freire tem destaque nas publicações.

Encontramos em algumas partes do livro Pedagogia Social (SILVA, SOUZA NETO, MOURA, 2009) referências da pedagogia social como teoria geral da educação social. Os sujeitos que estão vinculados a estas concepções reconhecem as seguintes denominações, que estão relacionadas: $\ominus$ educador social, e educador popular e e educador comunitário, ora como parte integrante da pedagogia social e/ou educação social, outra como complemento ou como característica das experiências da educação popular no Brasil.

Referente a educação popular, Paulo $(2013 ; 2018)$ resgata o processo histórico da sua origem. Segundo a autora, "a expressão popular na educação tem sentidos e significados diferentes, e até contraditórios. Nem sempre o popular esteve atrelado aos projetos emancipatórios enquanto resistência aos preceitos dominantes presentes em nossa sociedade." (PAULO, 2018, p. 131). Ao trabalhar os sentidos e significados da educação popular no mundo, ela faz a opção pela concepção crítica desde Paulo Freire.

Concernente à educação não escolar, não a compreendemos com o mesmo significado de educação formal, educação não formal e educação informal. Gohn (200।; 20 l0) aproxima a educação não formal de processos de intervenção pedagógica, sobretudo realizados em programas e projetos sociais das Organizações não Governamentais (ONGs), reconhecidas como terceiro setor, ajudando-nos a problematizar essa definição e a decidir pelo uso da expressão educação não escolar institucionalizada.

Severo (20I5), em sua pesquisa, declara a necessidade da reorientação curricular do curso de pedagogia, principalmente para a formação de pedagogos para atuar em contextos não escolares, não necessitando a criação de novos cursos. A essa necessidade, retomamos os sujeitos trabalhadores da educação não escolar, indicados no livro Pedagogia Social (MOURA, NETO, SILVA, 2009), os quais seriam educadores socais, populares e/ou comunitários. Frisamos a necessidade de produzir textos científicos sobre o contexto de atuação desses educadores e os entendimentos dos adjetivos que acompanham o termo educadores. Como prévia, sem a intenção de aprofundar o tema, concebemos que a questão do trabalho não pode estar separada das concepções de educação e de formação. Muitos educadores atuam em ONGs, em condições de precarização das relações de trabalho e de sobrevivência. Assim, torna-se

\footnotetext{
${ }^{2}$ Na segunda parte do livro: Pedagogia Social, localizamos a educação social como sinônimo de trabalho com indivíduos em situação de exclusão social - condições mínimas de sobrevivência (SILVA, SOUZA NETO, MOURA, 2009).

${ }^{3}$ Considera-se o livro Pedagogia Social a primeira obra com destaque nacional sobre esse tema. Participaram dela pesquisadores que trouxeram experiências dos países: Alemanha, Itália, Finlândia, Portugal, Espanha e Uruguai (SILVA, SOUZA NETO, MOURA, 2009).
} 
preferível a contratação de educadores voluntários ou com baixos salários em nome de um trabalho popular, comunitário e/ou social.

Paulo (2010; 2013) apresenta pesquisas empíricas que abordam essa temática. Conforme a autora, o educador popular não se caracteriza ou se destina a uma profissão. É o militante da educação popular. Em todo caso, um educador popular pode ser um professor ou um educador social, esses últimos qualificam profissões que constam na Classificação Brasileira de Ocupações. No caso do educador social, há um amplo movimento de regulamentação da profissão; e, embora haja grupos com diferentes posições (Projetos de Leis 5346/2009 e 328/2015), todos eles possuem um mesmo entendimento: o de que o educador social é uma profissão e deve ser reconhecida. Mas divergem quanto a regulamentação da profissão, tipo de formação (nível médio, superior, pedagogia social), concepção de educação (educação social ou outra não especificada) e o espaço de atuação (educação escolar ou não escolar). Dentre esses pontos, enfatizaremos, ao longo desse artigo, o da área da educação social e o da concepção de educação popular.

Trilla (1996) não separa as concepções de educação formal, informal e não formal. Em sua compreensão, a classificação em partes impossibilita a visão de totalidade (globalidade) da educação. Em seu entendimento, essas compreensões não são iguais, pois é na educação formal e não formal que identificamos intencionalidades explícitas, se comparadas com as da educação informal. No entanto, em publicações posteriores, o autor avança na apresentação dessas concepções, distinguindo a educação escolar da não escolar. Para Trilla (1996), nessa distinção, há critérios estruturais e metodológicos, os quais colaboram para a afirmação da nossa hipótese de que a educação não escolar é uma modalidade da educação que possui espaços diferenciados da escola, processos metodológicos semelhantes, mas com suas particularidades em relação à pedagogia escolar.

Não diferenciamos a educação não escolar da educação escolar pela obtenção ou não de títulos acadêmicos, pois em nossas pesquisas há espaços não escolares que emitem certificações que são aceitas na universidade. A educação não escolar tem características semelhantes à educação formal, já que possui formalidades, intenções, planejamentos, acompanhamentos e estruturas com regras próprias.

Como pode ser observado, neste texto, não separamos a educação formal da educação escolar e educação não escolar, pois ambas têm estruturas e projetos educativos diferentes, porém formalizados. Entendendo assim, são recentes as bibliografias que se aproximam dessa concepção alargada de educação formal no sentido de ser institucionalizada. Por isso, escolhemos as expressões educação escolar e educação não escolar.

Com relação à pesquisa bibliográfica, observaremos o tema da educação não escolar e o da educação popular presentes em estudos oriundos de pesquisas no âmbito da pós-graduação stricto sensu. Antecipamos a necessidade de tornar público mais estudos em nível de graduação, além da emergência 


\section{AFINAL O QUE ESTAMOS COMPREENDENDO COMO EDUCAÇÃO SOCIAL, EDUCAÇÃO POPULAR E EDUCAÇÃO NÃO ESCOLAR?}

Abordaremos pontos de vistas de estudantes-pesquisadores dos referidos temas, apontando as particularidades, aproximações e distanciamentos teóricos e epistemológicos que se configuram no exercício da compreensão e uso desses termos. Sublinha-se a necessidade de observar que, não por acaso, o conceito de pedagogia social consta no presente texto. Isso deve-se a pelo menos duas explicações, a saber: a primeira deriva-se, em alguns casos, do uso dela como sinônimo de educação social; e, a outra, porque alguns autores identificam a educação social como a prática da pedagogia social.

Ribas (20 | 4); em um estudo exaustivo envolvendo a temática da pedagogia social como referencial teórico para a educação social, nos traz elementos importantes para o início de um necessário e longo debate sobre o que seria a educação social no Brasil. Em sua pesquisa, nos mostra que na Espanha o educador social é diplomado em educação social, assim como em outros países da Europa. Na Alemanha, na Áustria, na Dinamarca, na Islândia, na Suécia e na Suíça, a profissão denomina-se pedagogo social, mas nem sempre se vale da concepção de educação social. Utiliza-se termos como: socioeducação, campo social e pedagogia social.

Na Espanha, a educação social nem sempre se dá no contexto da educação não escolar. É o alemão Paul Natorp, um autor clássico, que tem influenciado a definição de educação social na Espanha, principalmente com seu livro, publicado em 1899, abordando a Pedagogia Social. Inclusive, Natorp é considerado um dos educadores que foi influenciado por Pestalozzi, escrevendo sobre suas ideias pedagógicas (NATORP, 1931; WÜRTH, 197I).

Pestalozzi, influenciado por uma história de sucessivas guerras, geradoras de um contexto de desigualdade social, preocupa-se com a educação dos pobres, defendendo uma reforma social em que a educação tenha por base a assistência social. Os pobres com quem ele trabalhou foram os menores desajustados; assim, todo seu empenho estava centrado na luta para defender uma educação prática para reajustar esses menores pobres na e para a sociedade. Foi reconhecido como pai dos pobres órfãos, em virtude do trabalho no orfanato, preconizado por ele. Humanista, espontaneista e idealista, preocupou-se com os problemas sociais gerados pela miséria e pobreza, lutando contra as injustiças sociais, sendo a favor da educação formal (escolar) assistencialista (PAULO, 20 I 8).

Conforme Würth (I97|), a pedagogia de Pestalozzi nasceu do trabalho manual (prático), dele indo para as aulas (teoria), sendo, na atualidade, uma concepção acolhida por alguns grupos de pesquisadores 
brasileiros da pedagogia social enquanto ciência da educação social. Importante destacar que Pestalozzi foi influenciado pelas ideias de Rousseau, que apresenta a pedagogia como ciência desde uma educação utilitária (WÜRTH, 197I; ROUSSEAU, 1995).

Nuñez (1999) nos diz que a pedagogia social é o marco teórico da educação social. Na obra organizada por Nuñez (2002), é possível encontrar textos de José Antonio Caride Gómez, José Ortega Esteban, Juan Sáez Carreras, Hebe Tizio e Graciela Frigerio. Nos quais encontramos aproximações entre a pedagogia social e o contexto do surgimento do que se identifica como educação social no Brasil. De um modo geral, colocam que a educação social é um desafio da pedagogia social. Assim como no Brasil, na Espanha a pedagogia social apresenta-se como formadora dos profissionais denominados como educadores sociais. Outro exemplo dessa acepção é o de Caride (2005), concebendo a educação social enquanto objeto de estudo da pedagogia social, definindo-a como ciência do social, disciplina e profissão.

É notável destacar a influência no Brasil das concepções advindas da Espanha. Conforme constatamos na revisão bibliográfica, existem aproximações no campo das experiências, como é o caso da figura do educador social atuando com a população em situação de vulnerabilidade social. Na Espanha, vincula-se a atuação dos educadores sociais numa determinada área: a da educação social, cujo entendimento chega ao Brasil entre os anos 2007 a 20 I 8. Como amostra dessa aproximação, sinalizamos que a primeira universidade, a qual temos conhecimento, com área de educação social institucionalizada é a Universidade Federal do Rio Grande do Sul (UFRGS) por meio da Faculdade de Educação (FACED) (PAULO, 20I8).

No cenário espanhol, Esteban, Caride Gómez e Úcar (2013) contribuem na aproximação com os estudos que vêm sendo produzidos no Brasil. Antes de 2007, não se discutia, pelo menos em publicações científicas, a relação entre profissão do educador social e a sua área de atuação. Identifica-se essa afinidade com o Projeto de Lei de No 5346/2009, quando a educação social é caracterizada como área profissional. Além desse projeto, existe um outro, n³28, de 2015 (BRASIL, 20I5), que busca normatizar essa profissão. Entendemos, à luz dos estudos de Bauli (20/8), que, diferente do Projeto de Lei de $n^{\circ}$ 5346/2009, este último, de 20I 5, é o mais adequado, porque busca regulamentar a profissão e não a área da educação social. Entretanto, esse não é um entendimento de consenso, sobretudo no tocante ao que regulamentar (área ou profissão) e qual o nível de formação (educação básica / ensino médio ou educação superior) deve ser exigido para o exercício da profissão de educador social.

Em outubro de 20II, participando no III Congresso Iberoamericano de Pedagogia Social e XXIV Seminário Interuniversitário de Pedagogia Social, realizado no Campus Central da Universidade em Canoas, Rio Grande do Sul, percebemos um início de um percurso de estudos, mais acentuados, sobre educação não escolar, especialmente na divulgação de experiências e projetos educativos realizados nas organizações da sociedade civil do terceiro setor. Curiosamente, o tema desse encontro foi: A Pedagogia 
Social no diálogo Educação Popular - Educação Social. Entre os eixos temáticos que constavam na programação do evento, vimos: A Pedagogia Social como referente científico e acadêmico no diálogo Educação Popular - Educação Social (PAULO, 20।3).

Esse eixo suscitou reflexões sobre o que seria educação social no Brasil, especialmente na Associação de Educadores Populares de Porto Alegre (AEPPA), existente desde a década 1990. Desde 20 I0, a AEPPA sedia encontros formativos sobre o tema da educação popular, da pedagogia, da educação infantil, da Educação de Jovens e Adultos (EJA) e da educação não escolar (PAULO, 20।3). Participam desses grupos pessoas interessadas em conhecer, estudar, pesquisar e sistematizar experiências relacionadas a esses assuntos, independente da sua formação. Registros desses encontros podem ser localizados em Flores (2007), Paulo (20 I0; 20 I3), Lord (20 I I), Fuhrmann e Paulo (20 I4).

Conforme Paulo (20 I3), a participação dos membros da AEPPA no III Congresso Iberoamericano de Pedagogia Social e XXIV Seminário Interuniversitário de Pedagogia Social culminou, no ano seguinte (20 I2), na realização de encontros formativos para refletir sobre o que é ser um educador popular e quais práticas educativas e políticas são possíveis no contexto de trabalho realizado em organizações não governamentais. Em 2013, organizou-se um seminário sobre: Quem são os trabalhadores das Organizações não Governamentais (ONGs) que executam as políticas da educação e da assistência nas comunidades periféricas de Porto Alegre? Retomou-se os temas advindos desde o surgimento desse movimento de educadores populares, a começar pelos seguintes contextos:

Por um lado, como consequência das exigências do novo ordenamento legal federal, educadoras infantis de Porto Alegre, a partir de suas instituições, se organizaram para reivindicar a oferta de formação específica para sua atuação nas creches conveniadas. Foi criada a Associação de Educadores Populares - AEPPA, que contribui até hoje para desencadear outros movimentos reivindicatórios na cidade. Por outro lado, os resultados da pesquisa fizeram com que o município passasse a pensar formas de qualificação para as profissionais das CCs [creches conveniadas], além da formação continuada, que, pela necessidade apontada, teriam que ir na direção de políticas que integrassem a conclusão de estudos regulares à profissionalização. (FLORES, 2007, p. 162).

Essa classe social e profissional está associada à luta pela formação e reconhecimento do trabalho exercido por estas/es Educadoras/es Populares que normalmente são consideradas tias ou tios e não educadores/as. No entanto, para compreender o contexto histórico do trabalho deste grupo, se faz necessário estudar os limites, impasses e desafios desses/as trabalhadoras/es no âmbito da educação não escolar que possui convênio com o poder público. (PAULO, 20 I0, p. 19).

No que diz respeito ao estudo desta tese, a consideração é a de que o estudo do movimento de educadores populares em Porto Alegre extrapole os campos de ação deste ator coletivo. Suas propostas trazem implicações sobre outros espaços, em especial sobre as representações na esfera pública acerca do que cabe como educação das periferias, como condições de trabalho dos educadores populares e como justiça social a partir da democratização do serviço educacional. (LORD, 20II, p. 4I).

A partir do exposto, a AEPPA, mesmo com seus limites, ainda é um dos espaços de discussão, mobilização, esperança e contestação, podendo se constituir como um lugar de enfrentamento massivo contra a precarização do emprego, fortalecimento, reconhecimento e valorização do trabalho desenvolvido pelos (as) educadores(as) populares das comunidades. Sendo assim, como espaço de luta, tem o potencial de provocar processos de formações político-pedagógicas que venham de encontro às políticas que negam a educação popular. (PAULO, 2013, p I62). 
Essa exemplificação colabora para avançarmos nas discussões sobre educação popular, educação não escolar e educação social. Os fragmentos acima, embora retratando experiências muito particulares de formação, estudo e pesquisa sobre esses temas, sustentam uma constatação: o trabalho de educadores, atuantes em contextos não escolares, vem sendo realizado, majoritariamente, nas organizações do terceiro setor, situadas nas comunidades periféricas das cidades, as quais vêm atendendo pautas específicas de pessoas em situação de vulnerabilidade social. Esses educadores realizam práticas educativas voltadas para crianças, adolescentes, jovens, adultos e idosos. Muitas vezes, esse contexto de trabalho situado em espaços não escolares e com a realidade de pobreza é compreendido como educação social. Para demostrar essas aproximações basta um breve levantamento bibliográfico nas produções de Teses e Dissertações a partir do portal da Coordenação de Aperfeiçoamento de Pessoal de Nível Superior (CAPES), principalmente após 2007 (PAULO, 2018).

Matuda (2009) apresenta a educação social como sinônimo de educação não escolar a partir do Telecentro comunitário. Contudo, fala na área de educação social, com conteúdo e abordagens específicas. Nessa dissertação, localizamos a educação dividida em três categorias, como fazem outros tantos teóricos que vêm discorrendo sobre esse tema: educação formal, informal e não formal. Em seus argumentos teóricos, dialoga com Afonso (200l), que conceitua essa tríade não utilizando o termo educação social. Para ele, a educação não formal pode "ser relacionada com fatores muitos diversos, dentre os quais se pode salientar a crise da escola pública" (AFONSO, 200 I, p. 29). Alerta, entretanto, que o "não escolar não pode ser construído contra a escola, nem servir a quaisquer estratégias de destruição dos sistemas públicos de ensino, como parecem pretender alguns dos arautos da ideologia neoliberal." (AFONSO, 200 I, p. 3I).

Em síntese, a educação não formal é compreendida como campo de atuação, sinônimo do que estamos identificando como educação social em estudos localizados no levantamento bibliográfico sobre o tema, e que definimos aqui como educação não escolar.

Constatamos que a maioria das produções referentes à educação não escolar aproximam-se das políticas vinculadas à assistência social e de subtemas que se dirigem ao registro de diversas práticas educativas realizadas a partir de temas específicos: violência, direitos humanos, orçamento participativo, economia solidária, teatro do oprimido.

Também, temos aproximações com experiências de educação de jovens e adultos, de movimentos sociais, educação popular e formação de professores. Com relação à educação de jovens e adultos, entendemos que a relação com educação não escolar deve ser decorrente dos programas e políticas de alfabetização realizados fora da escola, mesmo sendo uma modalidade da educação escolar. Mais recentemente, foram produzidos trabalhos que tratam da educação de jovens e adultos realizada em espaços de privação de liberdade (PAULO, 2018). 
Alusivo aos movimentos sociais e à educação popular, muitos dos trabalhos carecem de aprofundamento sobre os entendimentos acerca das diferenças e semelhanças entre a educação não formal (movimento social) e a educação não escolar formalizada, aquela realizada pelas organizações não governamentais com regime de convênio ou termo de colaboração com o Estado, via execução de políticas sociais através de parceria público-privada. Salientamos um limite teórico e epistemológico no tocante à concepção de educação popular, que, não raras vezes, manifesta-se como sinônimo de educação não formal ou educação para pobres.

Ribeiro (2006) é uma das autoras que mais tem sido questionada sobre a sua compreensão no uso do termo educação social. Concordando com ela, assumimos a posição de que toda educação é social e que a educação popular declara uma posição de classe e um projeto de sociedade socialista. Por conta de questionamentos advindos inclusive de colegas que vêm pesquisando esse tema, esse texto apresenta o que é o social e o motivo pelo qual não o adjetivamos, uma vez que compreendemos que toda educação é social na sua essência. Por isso, a pergunta mais pertinente é: $\bigcirc$ que é educação?

Brandão (1983, p.68) afirma e reafirma em várias partes deste livro que "a educação é uma prática social." A educação é uma das dimensões da vida social, considerando que ela perpassa todas as outras dimensões (da economia, da saúde, da religião, da profissão, da cultura porque a compreendemos em seu sentido amplo, multidimensional, não categorizando em escolar e não escolar. A educação, no entanto, acontece e é concebida em contextos sociais diversos, consubstanciados por conflitos e disputas, mediados por normas regidas em legislações e/ou constituídas culturalmente, em decorrência de valores reconhecidos como verdades, especialmente oriundos de diferentes formações religiosas. Essas regras institucionalizadas ou instituintes objetivam amenizar e prevenir conflitos geradores de grandes polêmicas, as quais não negam o caráter social da educação.

Brandão ( 1983 ) aponta contextos de educação que colaboram na afirmação de que toda educação é social, não precisando caracterizá-la; como afirma Ribeiro (2006, p. 160), o "conceito de educação social porque o segundo termo da expressão, o "social", parece-me, num primeiro momento, configurar-se como uma redundância, ou figura de linguagem chamada pleonasmo." No caso da relação educação não escolar e seus múltiplos espaços de atuação (na comunidade, moradia e religiosa),

nas aldeias dos grupos tribais mais simples, todas as relações entre a criança e a natureza, guiadas de mais longe ou mais perto pela presença de adultos conhecedores, são situações de aprendizagem. A criança vê, entende, imita e aprende com a sabedoria que existe no próprio gesto de fazer a coisa. São também situações de aprendizagem aquelas em que as pessoas do grupo trocam bens materiais entre si ou trocam serviços e significados: na turma de caçada, no barco de pesca, no canto da cozinha da palhoça, na lavoura familiar ou comunitária de mandioca, nos grupos de brincadeiras de meninos e meninas, nas cerimônias religiosas. (BRANDÃO, 1983, p. 18).

Como observamos no trecho acima, as situações de ensino-aprendizagem não se dão somente na escola. Há um mediador nessas relações e nessas práticas educativas, que, normalmente, são 
direcionadas por alguém mais experiente ou vivenciadas com e entre os seus pares. Um exemplo desse modo de educar e educar-se pode ser verificado no excerto abaixo,

as meninas aprendem com as companheiras de idade, com as mães, as avós, as irmãs mais velhas, as velhas sábias da tribo, com esta ou aquela especialista em algum tipo de magia ou artesanato. Os meninos aprendem entre os jogos e brincadeiras de seus grupos de idade, aprendem com os pais, os irmãos-da-mãe, os avós, os guerreiros, com algum xamã (mago, feiticeiro), com os velhos em volta das fogueiras. Todos os agentes desta educação de aldeia criam de parte a parte as situações que, direta ou indiretamente, forçam iniciativas de aprendizagem e treinamento. (BRANDÃO, 1983, p. 19).

O autor aborda, acima, os lugares em que a educação está presente: todos. Em suas palavras, Brandão (1983, p.47) afirma que "a educação do homem existe por toda parte e, muito mais do que a escola, é o resultado da ação de todo o meio sociocultural sobre os seus participantes." Isto é, a educação é parte da nossa vida e se faz presente no trabalho, em casa, no templo, no barco e no ônibus, no campo e na cidade, no bar, no mercado, enfim, em todos os contextos sociais. Brandão (1983, p.82) define esses espaços como "espaço educacional não escolar".

Concernente à educação escolar, ela tem uma história atrelada à divisão social do trabalho, caracterizando-se pelo ensino formalizado e especializado com vistas à formação de trabalhadores assalariados. Com o passar dos anos, propostas e entendimentos diversos de educação escolar emergiram e foram difundidos. As concepções de escola tradicional livresca, escola nova, escola tecnicista, entre tantas outras, advêm desse movimento. Essas acepções surgiram em determinados tempos e contextos históricos e políticos; e, mesmo quando a proposta educacional se dirigia a uma metodologia mais libertária, sem diretividade na/da ação educativa, ou autoritária, no sentido de silenciadora, a educação não deixava de ser social.

A chamada educação social, no caso europeu, está correlacionada à crise pós II Guerra Mundial, aos processos de exclusão social e ao amparo aos vulneráveis do sistema. Na Espanha, uma série de questões foram e são pautadas em torno da educação: violência, pobreza, indisciplina, metodologias, família, crise da escola, entre outros temas, não expressando, explicitamente, o termo educação social. Cabanas (1977), influenciado por Rousseau e Platão, defende uma educação que se preocupe com os problemas sociais. Esse entendimento não está indissociável do que concebemos por educação desde a influência dos intelectuais liberais. Conforme Brandão (1983), a educação a partir dos referenciais liberais, disseminados desde as primeiras décadas do século $X X$, destina-se, pelo menos em nível das ideias, a democratizar o conhecimento dando acesso aos pobres a "uma escola mais dirigida à vida." (BRANDÃO, 1983, p. 87).

Schugurensky (20 I 6), ao apresentar a pedagogia social, trabalha com a educação popular de Paulo Freire. Para ele, "na América do Norte, o uso do termo pedagogia social é um fenômeno relativamente novo, mas as práticas sociais pedagógicas vêm sendo usadas faz um longo tempo" (SCHUGURENSKY, 
2016, p. 226 - tradução nossa). Schugurensky não faz uso da expressão educação social. Nesse artigo, o educador retoma as origens da pedagogia social (Alemanha) e a disseminação de publicações sobre o tema em livros e periódicos em outras línguas que não a inglesa. Pontua que, no caso de literatura inglesa, elas são recentes, sobretudo a partir dos anos de 200I em diante. Destaca que o interesse acadêmico pelo tema está intrinsecamente ligado à criação da primeira revista de pedagogia social em inglês, lançada em 2012 nos Estados Unidos. A repercussão resultou na criação de um curso de mestrado em pedagogia social: "el Máster en Pedagogía Social del Instituto de Educación del University College London, una escuela líder en educación calificada como número I mundial por el QS World University Rankings en 20 I5" (SHUGURENSKY, 2016, p. 228).

Em consequência da proliferação de publicações acerca da pedagogia social foi originado um curso de mestrado em pedagogia social e pedagogia cultural na Universidade do Estado do Arizona, universidade pública dos Estados Unidos. Conforme Schugurensky (2016), a criação desses dois programas de pósgraduação deu-se de forma independente e quase simultaneamente, sem comunicação entre eles. Em ambos os cursos há uma relação entre educação, democracia e intervenção social, cuja compreensão de educação pressupõe a vertente filosófica holística não clássica (cartesiana), isto é, conhecida como paradigma emergente da cosmovisão. Essa abordagem dialoga com o humanismo, utilizando-se do método hermenêutico.

Com relação a essa abordagem, associamos a vertente filosófica holística - mencionada anteriormente - ao que, no Brasil, identificamos como uma tentativa de conceituar a educação social: entre um referencial híbrido e plural, cuja presença da multidimensionalidade, muitas vezes, confunde, mistura e invisibiliza concepções oriundas de um contexto social, político, educacional, cultural e econômico, como é o caso da educação popular no Brasil e na América Latina.

Mas é importante destacar que, mesmo no contexto norte-americano, Schugurensky (2016) apresenta três tradições da pedagogia social como pesquisa interventiva: a educação indígena, educação progressista e aprendizado dos movimentos sociais. No programa de pós-graduação em pedagogia social na América do Norte, concentrou-se em estudos realizados no contexto da educação indígena (vida comunitária, cooperação, colaboração e aprendizagem através da experiência).

No caso da educação progressista, destacam-se os seguintes temas: trabalho social, pensamento crítico, democracia e construção de comunidades. John Dewey reconhecido como defensor da democracia, e Jane Addams conhecida como "a mãe do trabalho social", foram inspiradores dessa tradição da pedagogia social. É relevante destacar a formação de ambos: Dewey era filosofo, e Addams, assistente social. Ainda, segundo Schugurensky (2016), as contribuições de John Dewey e Jane Addams foram constitutivas para o desenvolvimento de pedagogia na América do Norte, na qual as aprendizagens acontecem mediante o compartilhamento de experiências que, no regime democrático, devem colaborar 
na resolução de problemas sociais. Por fim, a terceira tradição norte-americana que influencia a pedagogia social é o aprendizado do movimento social. Nesta, destacam-se as seguintes características: engajamento em ações para conquistar mudanças, redes de interação, crenças compartilhadas, solidariedade e ação coletiva. Outra ênfase está no processo de ensinar e aprender nos movimentos sociais e a relação com a horizontalidade, cuja dimensão efetiva-se mediante redes de interação, e destaca, para exemplificar, o Fórum Social Mundial, como espaço privilegiado de aprendizagens mútuas.

Uma referência citada foi Myles Horton e Jane Addams, sobretudo por conta das experiências destes na defesa de escolas populares, educação comunitária e mudança social. Horton e Freire ( 1990), argumentaram que a mudança social só poderia acontecer por meio da participação e mobilização das comunidades no seu processo educativo. Ainda, localizamos outras influências da pedagogia social norteamericana, entre elas a educação popular e a pesquisa participativa, além de processos educativos realizados fora da escola. Mas, neste momento, vamos explorar a influência da educação popular e da pesquisa-ação participativa. Para Schugurensky (2016, p. 240, tradução nossa):

A pedagogia social na América do Norte também é inspirada pela educação popular, um campo de prática que se originou na América Latina, na década de 1970, e, por sua vez, foi fortemente influenciado pelo trabalho de Paulo Freire, um educador brasileiro que propôs um projeto político-pedagógico para fomentar justiça, democracia e humanização. [...]. Na abordagem de Freire, a educação é entendida como práxis: reflexão e ação sobre o mundo para transformá-lo. Dentro desse modelo, o processo de transformação como práxis implica um movimento dialético em que a reflexão ação e ação interagem para produzir a conscientização.

O autor menciona as ideias de Freire e Horton (1990) sobre educação e mudança social, citando as conversas entre estes dois educadores. Faz alusão ao Orlando Fals Borda em razão do seu modelo de pesquisa-ação participativa que visava democratizar a produção de conhecimento, e, com isso, a "pesquisaação participativa, juntamente com a prática de avaliação participativa, tem sido ligada à pedagogia social em vários estudos." (SCHUGURENSKY, 2016, p. 24I, tradução nossa).

Sobre os processos educativos realizados fora da escola e a conexão com a pedagogia social, ela associa-se a um tipo particular de organização da economia social, com trabalho comunitário, ação voluntária e as cooperativas. Ademais, a presença do tema da participação correlacionada a democracia participativa é uma das tradições que vai ser identificada como tema da pedagogia social, e, com isso, os processos de decisão compartilhada entre Estado e sociedade civil.

Schugurensky (2016) contribui para nos situarmos no contexto do surgimento da pedagogia social, suas perspectivas teóricas e metodológicas. Nesse texto, é possível identificar as distintas compreensões sobre educação e suas influências filosóficas e sociológicas. Constatamos aproximações e distanciamentos com o que conhecemos, no campo teórico, por pedagogia social, no Brasil.

As primeiras discussões sobre esse tema, no caso brasileiro, ocorreram nos anos 2000. Até então, predominaram as concepções de educação não formal de Gohn (200 I ; 20 I 0), ao tratar da educação fora 
da escola. Os espaços de educação não escolar não são novos, eles existiam desde os primeiros movimentos populares e universidades populares, que ofereciam oficinas, seminários e reuniões formativas às comunidades. Essas experiências educativas são originárias do movimento dos operários anarquistas dos anos de 1920.

Nos anos 1950 e 1960, muitas experiências de educação não escolar ocorreram a partir de movimentos sociais populares, sobretudo os ligados à ala da igreja católica progressista. Nessa época, a educação de adultos não era dever do Estado, tampouco direito do cidadão. Foi nesse período que campanhas e programas de alfabetização de adultos, na perspectiva da educação popular, se disseminaram, principalmente no nordeste do país (GOHN, 200I; 20I0).

Com o processo de globalização mundial, sob a égide do modelo hegemônico capitalista, grandes transformações originaram-se desse redesenho de estrutura desse modelo de sociedade. Iniciou-se experiências de educação não escolar formalizadas, tanto no âmbito estatal como no contexto das organizações não governamentais, de educação infantil executada pelas comunidades, entre outras formas de oferta de práticas e políticas educativas destinadas à classe popular.

Chamamos a atenção para o contexto histórico e político em que a denominada educação social passa a compor parte da agenda demandatória de temas educacionais. Ocorre que, nesse processo de globalização econômica, a educação social, tal como ela foi concebida historicamente, sobretudo no contexto europeu, não vem ao encontro da emancipação humana, que pressupõe uma formação omnilateral, o que a educação popular com base em Freire tem por objetivo.

O homem e a mulher omnilateral consiste em uma formação política com bases teóricas e epistemológicas que visam construir teoria que não se separa da prática social, associando-se a um projeto de transformações sociais - indissociável da formação humana individual e coletiva - processo histórico de reflexão, de criação e de resistência. Essa compreensão assume a dimensão da teoria crítica, diferente das leituras interpretativas de educação numa perspectiva pós-crítica, cuja interpretação da realidade valoriza a subjetividade, priorizando o indivíduo em relação ao social. Em outras palavras, na teoria pós-crítica o trabalho com pessoa em situação de vulnerabilidade social parte do objetivo de empoderá-la para o exercício da cidadania e do reconhecimento de suas identidades, com vista ao cumprimento do arcabouço legal, entre eles a Constituição Federal (BRASIL, 1988), o Estatuto da Criança e do Adolescente (BRASIL, 1990), a Lei Orgânica da Assistência Social e a Lei de Diretrizes e Bases da Educação (BRASIL, I993). Essa educação na afirmação da identidade, via pedagogia dos direitos, não trabalha com a concepção de emancipação produzida pela teoria crítica. Talvez quem, há mais tempo, ensaiou essa aproximação entre regulação, direitos e exclusão foi Gadotti (2012, p.26-27) quando afirma que é "a educação social que ganhará um status com esse reconhecimento estatal que garante o exercício dos direitos trabalhistas desses 
trabalhadores e trabalhadoras. Enfim, ganharão sobretudo as populações que vivem em situação de risco pessoal e social".

Aqui no Brasil, como já vem sendo constatado por Paulo (2010; 2013; 20 I8), e Flores (2007), muitas experiências educativas realizadas em contextos não escolares, às vezes denominadas como educação não formal e outras, são assumidas como educação social. Ambas as autoras concebem que essa definição é discutível porque ela encontra-se em construção, é polissêmica e, até, problemática, quando admitida como negação da escola ou como nova concepção de educação, utilizando-se de referenciais clássicos da educação popular. Paulo (2013) não classifica a educação não escolar em educação não formal ou educação informal. Para ela, a educação não escolar pode ser formalizada e não formalizada. A autora sugere, ainda, que apontamentos devem ser observados:

।. O termo educação não-formal não é sinônimo de informalidade. Como exemplo, citamos o caso dos educadores sociais que atuam no Serviço de convivência e Fortalecimento de Vínculos (SCFV). O contexto de trabalho é não escolar, mas com formalização (horário, currículo, planejamento, acompanhamento, etc.).

2. A expressão educação social não é utilizada por Paulo (2013) porque compreende que toda educação é, na sua essência, social. Toda educação, seja ela crítica ou autoritária, se dá no contexto social. Para a autora, no Brasil, tem se utilizado os referenciais da educação popular para conceituar a educação social, e, com isso, o movimento de criação de um conceito, utilizando-se das experiências da educação popular, apresenta-se problemático.

3. A negação da educação popular com base em Paulo Freire como pressuposto teóricometodológico de práticas educativas, escolares e não escolares, e como sinônimo de educação popular, negligencia a história da educação popular no Brasil. Isto é, "o conceito de educação social oculta o de educação popular, encharcado de história, ou seja, de luta das camadas populares por educação pública de qualidade." (RIBEIRO, 2006, p. 170-17I).

Os primeiros apontamentos, destinados a compreendermos a expressão social na educação (educação social) e o uso do termo educação não-formal não como sinônimo de não institucionalizado, são um caminho processual de compreensão das múltiplas possibilidades de estar e fazer educação como consta em Brandão (1983). Sacristán e Goméz (2000), ao fazerem uma leitura da função social da escola, nos dizem que nem sempre o processo de socialização é libertador, podendo ser conservador, garantindo, assim, "a reprodução social e cultural para a sobrevivência dessa mesma sociedade" (SACRISTÁN, GOMÉZ, 2000, p. 14), capitalista e desigual. Essa é a socialização do indivíduo e não do coletivo.

Além dessa função reprodutora, outra se aproxima de algumas das políticas que visam reduzir ou minimizar as situações de vulnerabilidade social, a função compensatória: "atenuar, em parte, os efeitos da desigualdade e preparar cada indivíduo para lutar e se defender nas melhores condições possíveis, no 
cenário social" (SACRISTÁN, GOMÉZ, 2000, p. 24). Os mecanismos de efetivação dessa função são variados, entre eles, as políticas compensatórias sem vinculação de luta e engajamento com um projeto de sociedade não capitalista (socialista). Nesses casos, as políticas de educação propõem práticas de educação social de compensação histórica da exclusão social, utilizando-se de recursos linguísticos que visam mudanças a serem provocadas por um trabalho colaborativo (equipe) e flexibilizado entre áreas e com diferentes profissionais, utilizando-se de pluralidades teóricas e ancorado na pedagogia das competências multidimensionais, via garantia da pedagogia dos direitos.

Essas duas funções (reprodutora e compensatória) também educam, mas não visam a transformação social. Entre as funções reprodutora e compensatória há uma educativa compreensiva (Sacristán e Goméz, 2000), diferente da função transformadora, afinada com a concepção de educação popular. Mesmo que tenhamos partido do mapeamento de funções da escola (sentido restrito de educação) apresentado por Sacristán e Goméz (2000), sustentamos o argumento de que não há educação que não seja social. Há diferentes concepções de educação, e teorias que, nelas, estão implicadas. No caso brasileiro, há usos da expressão de educação social com um referencial da educação popular, que, como vimos, está atrelada à teoria crítica, a qual objetiva uma educação transformadora das estruturas sociais, não só das conjunturas.

$(\operatorname{Re})$ significando o sentido de socialização, a chamada educação social é social seja de ordem primária (socialização direta mediada por pessoas na educação presencial) ou secundária (socialização mediada por tecnologias, construída por pessoas, no caso da educação a distância). De qualquer um dos modos, a educação não deixa de ser social. O terceiro ponto é o da utilização de expressões linguísticas, de referencial teórico e de experiências da educação popular com base em Paulo Freire, como sendo educação social. Utiliza-se a "nova concepção" de educação, a educação social, com esses argumentos teóricos. Compreendemos que esse entendimento prático-teórico é equivocado e anula uma história da educação construída no Brasil e na América latina, a da educação popular. É problemático porque os pressupostos teórico-metodológicos de práticas educativas fundamentadas na educação popular, seja em espaços escolares e não escolares, pressupõe uma teoria crítica visando um projeto de sociedade emancipatório, o qual exige a militância de educadores-educandos. Essa acepção de educação, muitas vezes, é identificada por autores que inauguram essa "nova concepção" de educação social no Brasil. Ou seja, esses educadores-pesquisadores da educação social, em um primeiro momento, não são antagônicos em suas compreensões de educação popular de educadores-pesquisadores da educação popular, até porque ambos vêm utilizando referências semelhantes e iguais para concepções diferentes. E, não estamos afirmando a inexistência e a desnecessidade de uma concepção de educação que abarque esses novos contextos educativos, tampouco desvalorizando ou desmerecendo o trabalho de pesquisadores da 
educação social. Por essas razões, de preocupação, que esse é um estudo inicial que aponta a necessidade de desvelamento desse fenômeno, a ser problematizado e investigado com e entre outros pesquisadores.

Nos preocupa, nesse quadro, a ocultação da educação popular, como nos alerta Ribeiro (2006), que nos previne quanto ao que tratamos das teorias imbricadas em cada uma das concepções, advertindo que devemos nos preocupar quando em

análises e relatos de algumas experiências é possível perceber um ocultamento de concepções, métodos e práticas de educação popular historicamente construídos pelos movimentos sociais, como se a educação social pensada em espaços formais, diferenciados dos que são produzidos por aqueles movimentos, pudesse avançar para a conquista da cidadania. (RIBEIRO, 2006, p. 168-169).

Sobre a história da educação popular, podemos encontrá-la em muitos livros e artigos. Neste artigo, citaremos algumas das referências, as quais podem ser consultadas; uma das concepções é de Paludo (2015, p.226)

O 'Movimento de Educação Popular' se fez no interior desse processo, na direção da construção de fazer do povo expressão política de si mesmo, por meio de organizações populares autônomas, imbuídas do desejo de construir o "poder popular". Enquanto Movimento, a EP cumpriu um forte papel de ação cultural no interior do campo e para além dele, constituindo-se em mediação entre a realidade objetiva e o projeto de futuro em construção. Por meio dele, articulado aos processos de luta e resistência, ia-se recompondo a representação do real enquanto totalidade, superando a fragmentação, na direção de uma concepção 'ético-política'.

A outra concepção é de Paulo (2018, p. 16),

educação popular, aqui, compreendida como concepção teórico-prática emancipatória, cujas lutas são por projetar, fomentar, produzir e construir alternativas revolucionárias, tanto para a sociedade (luta mais ampla) quanto para outras pautas presentes em espaços escolares e não escolares. Inegavelmente, as minhas referências fundamentam propostas concretas que se opõem aos projetos de educação e de sociedade opressoras e desumanizadoras. Dessa maneira, buscase promover propostas de ensino-aprendizagem e visões de mundo à luz de questionamentos reflexivos e de ações que se opõem ao modelo capitalista vigente. É por isso que essa concepção de educação popular implica discutir economia política, bem como questões sociais, políticas, pedagógicas, epistemológicas e culturais, até porque essa concepção é uma das principais referências dos movimentos sociais populares, base das lutas políticas contra a perversidade da economia política capitalista.

Em síntese, a educação popular é uma concepção de educação que não trabalha com as políticas e práticas pedagógicas de cunho reprodutor, assistencialista, compensador ou apenas de compreender a realidade e minimizar as situações com metodologias caracterizadas como participativas. A educação popular é revolucionária, rebelde e transgressora. Utilizando Freire (1987) como uma das referências teóricas da educação popular, estamos caracterizando o popular com sentido crítico e emancipatório.

Paulo (20 |8), para distinguir os usos do popular, optou pela educação popular freiriana. Uma das explicações foi a seguinte:

porque o uso da expressão educação popular não é próprio de Freire, possuindo, portanto, sentidos e significados diversos, [...]. Depois, porque Paulo Freire é uma referência básica da 
educação popular no Brasil [...]. Essa trajetória está vinculada à pedagogia de Freire." (PAULO, 2018, p. 2I).

Também, porque o popular sem o sentido crítico pode significar educação do popular (pobre) ou a popularização da educação (acesso às políticas sociais).

\section{$3 \quad$ NOTAS PARA A CONTINUIDADE DAS PESQUISAS}

O presente estudo possibilitou identificar que no Brasil não temos uma concepção de educação social. Há uma infinidade de definições e quase todas utilizam-se de Paulo Freire para fundamentá-las, autor esse que, na verdade, é defensor da educação popular e não do que vem sendo chamado de educação social. Em outras palavras, o que vem sendo denominada como educação social é, sobretudo, o espaço de realização de práticas não escolares realizadas com um público definido: pessoa em situação de vulnerabilidade social. Nesse caso, o mais coerente seria titularmos de educação não escolar. Sobre essa categoria (não escolar), podemos afirmar que ela é discutível, principalmente porque abarca contextos do que conhecemos como educação informal e não formal.

A definição de educação não escolar tem que ser descrita em seu tempo e espaço, já que a maioria dos nossos estudos acontece em contextos não escolares institucionalizados (possui horários, regras institucionais, cumprimento de legislações, planejamentos). Defendemos que a educação não escolar seja compreendida como uma modalidade de educação e não como uma nova área, tampouco como categoria da educação, embora possa ser descrita como tal.

Sobre a pedagogia social, quando vinculada a uma vertente libertadora, mencionada na obra organizada por Silva, Souza Neto e Rogério Moura (2009), identificamos aproximações com Paulo Freire e com a teoria crítica. Portanto, nesse caso e em nossa leitura, existem afinidades com a pedagogia socialista. Porém, quando tratada como teoria da educação social, não nos aproximamos dessa concepção, por entender que teoria e prática não se separam. Quem têm feito essa individualização querendo dar identidades aos objetos e aos sujeitos individualizados são estudiosos da perspectiva da teoria pós-crítica, abandonando o caráter de classe.

Em conformidade com a teoria crítica, as concepções e compreensões acerca da educação social, da educação popular e da educação não escolar não possuem semelhanças, são distintas e díspares. A educação popular, na sua gênese, possui uma diretividade político-pedagógica com vistas à emancipação humana, que, portanto, exige construir espaços de disputas de projetos, tendo como ponto de partida a realidade de vida dos oprimidos.

Considerando as particularidades de cada uma das concepções, a educação não escolar, sendo uma modalidade de educação, pode estar ancorada na perspectiva crítica, pós crítica ou tradicional, nas 
suas complexas manifestações. Se fundamentada na educação popular de Paulo Freire, por exemplo, há aproximações nas dimensões políticas, pedagógicas, metodológicas e epistemológicas. Mas, por outro lado, Freire muitas vezes é utilizado na educação não escolar como apêndice ou como um autor que contribui no trabalho com metodologias participativas. Nesse caso, não existe aproximação radical com a educação popular crítica. Ao mesmo tempo, a educação popular pode ser compreendida como popularização da educação, e, assim concebida, teremos aproximações com perspectivas da educação popular assistencialista ou com a garantia de direitos, a pedagogia dos direitos, que nem sempre tem como horizonte disputar projetos de sociedade. Esse é um dos distanciamentos teóricos e epistemológicos que se apresentam no debate em torno da educação popular, do uso de Paulo Freire e da educação não escolar.

No tocante à denominada educação social, como explicitado ao longo do texto, ela não se configura como uma concepção definida (crítica ou não crítica, escolar ou não escolar, para todos ou para pessoas em situação de vulnerabilidade social), carecendo de definições que não sejam, apenas, substitutas da educação não escolar e ou da educação popular.

No exercício de análise e compreensão do uso desse termo, estamos convencidos de que não há educação que não seja social. Concordando com Ribeiro (2006), adjetivar a educação com o social significa dizer que há educação que não seja social; mas, como observamos nas bibliografias, a concepção de educação é alargada e, ela em si, é um processo de socialização nos múltiplos contextos educativos, os quais nem sempre estão consubstanciados por uma teoria socialista, como é o caso da educação popular. Então, a utilização da expressão educação social para caracterizar práticas educativas não escolares é um erro epistemológico e político, porque, em uma primeira análise, está atravessado por compreensões distantes do que conhecemos na história da educação (CAMBI, 1999). Desde a Grécia, todos os tipos de educação foram sociais, mas o social não era para todos, assim como o popular (PAULO, 20।3; 20 I8).

Esse é um ponto a ser tratado em outros textos. $O$ social nem sempre foi concebido como inclusão de todas as pessoas, porque nem todas as pessoas eram, no decorrer da história, consideradas cidadãs de direitos. Porém, em todos os casos, a educação teve o papel de socializar conhecimentos e comportamentos. Um exemplo clássico são as concepções de educação em Esparta e Atenas: cada qual com seus objetivos e suas vertentes - não similares - pressupunha a socialização de saberes e culturas, atreladas aos seus respectivos projetos societários (PAULO, 20I8).

O estudo revelou, no caso brasileiro, que o uso da educação social é tautológico, ou seja, é desnecessário utilizar o social como complemento da educação. Não foi identificado um conceito explícito de significado de educação social no Brasil, pois o que verificamos é a semelhança ou até o mesmo significado e sentido, quando deseja-se tratar da educação não escolar ou da educação para os sujeitos em situação de vulnerabilidade social. 
Percebemos, durante a pesquisa bibliográfica, a presença de uma multidimensionalidade na compreensão dos três conceitos: educação popular, educação não escolar e educação social, nas concepções crítica e pós-crítica. Na primeira, a educação popular não é sinônimo de educação não escolar e não é o mesmo que educação social. Para essa vertente, a luta político-pedagógica se insere na contramão da manutenção da opressão, sendo os espaços educativos lugares de diálogo e problematização de múltiplos saberes, privilegiando a manifestação das diferentes realidades sociais e os conflitos inerentes a elas.

Em nenhuma das leituras realizadas constatou-se as três concepções associadas à teoria tradicional. Mas reconhecemos, nessas leituras, que nem sempre a educação popular, mesmo quando Freire é referenciado, tem o significado teórico-prático de uma educação libertadora e da formação omnilateral atreladas a um projeto de sociedade socialista.

Na perspectiva pós-critica, a educação popular é entendida como trabalho educativo realizado a partir das experiências individuais dos educandos, visando atribuir às práticas pedagógicas o papel de potencializar o protagonismo dos sujeitos. Em alguns casos, utiliza-se educação popular e educação social com o mesmo sentido. Há um desvio das discussões referentes às classes sociais para as múltiplas identidades. Além disso, observa-se a junção das duas vertentes em textos mais recentes (2010 em diante) que investigam a pedagogia social e a educação social, sobretudo no tocante às metodologias participativas e ao uso de Paulo Freire na concepção de educação.

No geral, em muitos artigos sobre educação não escolar, localizamos a multidimensionalidade, principalmente nos textos de autores que utilizam o termo educação social ou educação não escolar, e, em menor medida, textos sobre educação popular e educação social juntas. Enfim, não temos um conceito explícito do que seria a educação social no Brasil, porém existe, em alguns casos, no uso dessa expressão, semelhanças ou até o mesmo significado e sentido, do que conhecemos como educação popular.

\section{REFERÊNCIAS}

AFONSO, Almerindo Janela. Os lugares da educação. In: SIMSON, Olga Rodrigues de Moraes Von; PARK, Margareth Brandini; FERNANDES, Renata Sieiro (org.) Educação Não-formal: cenários da criação. Ied. Campinas: Editora da Unicamp, 2001 . p. 29 - 38.

BAULI, Régis Alan. Educador social no brasil: profissionalização e normatização.20 I8. Tese (Doutorado em Educação) - Universidade Estadual de Maringá, Maringá, 2018.

BRANDÃO, Carlos Rodrigues. O que é Educação. São Paulo: Brasiliense. 1983.

BRASIL. [Constituição (1988)]. Constituição da República Federativa do Brasil de 1988. Diário Oficial da União: seção I, Brasília, DF, n. 191 -A, p. I, 5 out. 1988. Legislação Informatizada - Constituição de 1988 - Publicação Original. Disponível em: w2.camara. 
leg.br/legin/fed/consti/| 988/constituicao- | 988-5-outubro- | 988-322 | 42-publicacaooriginal- I -pl.html. Acesso em: 19 out. 2019.

BRASIL. Lei no 8.069, de 13 de julho de 1990. Dispõe sobre o Estatuto da Criança e do Adolescente e dá outras providências. Diário Oficial [da] República Federativa do Brasil, Brasília, DF, 16 jul. 1990. Disponível em: http://www.planalto.gov.br/ccivil_03/LEIS/L8069.htm\#art266. Acesso em: 16 out. 2019.

BRASIL. lei n 8.742, de 7 de dezembro de 1993. Dispõe sobre a organização da Assistência Social e dá outras providências. Diário Oficial [da] República Federativa do Brasil, Brasília, DF, 7 de dezembro de 1993. Disponível em: http://www.planalto.gov.br/ccivil_03/eis/18742compilado.htm. Acesso em: 16 out. 2019.

BRASIL. Lei n. 328 de 2015. Dispõe sobre a regulamentação da profissão de educadora e educador social e dá outras providências. Diário Oficial da

União: Brasília, DF, p. I-5, 4 abr. 2019. Disponível em: https://legis.senado.leg.br/sdleggetter/documento?dm=4427478\&ts= |593913637990\&disposition=inline. Acesso em: 4 out. 2019.

CABANAS, José Maria Quintana. Sociología de la educación. La enseñanza como sistema social. Barcelona: Editorial Hispano-Europea, 1977.

CAMBI, Franco. História da pedagogia. São Paulo: Editora da Unesp, 1999.

CARIDE, José Antonio. Las fronteras de la pedagogia social: perspectivas científica e histórica. Barcelona: Gedisa, 2005.

ESTEBAN, José Ortega; CARIDE GÓMEZ, José; ÚCAR, Xavier. La Pedagogía Social em la formación profesionalización de los educadores y las educadoras sociales, o de cuando el passado construye futuros. Revista de Educación Social, Barcelona, n. 17, p. I-24, jul. 2013.

FLORES, Maria Luiza Rodrigues. Movimento e Complexidade na Garantia do Direito à Educação Infantil: um estudo sobre políticas públicas em Porto Alegre (1 989-2004). 2007 Tese (Doutorado em Educação) Universidade Federal do Rio Grande do Sul. Porto Alegre, 2007.

FREIRE, Paulo. Pedagogia do oprimido. São Paulo: Paz e Terra, 1987.

FREIRE, Paulo. A importância do ato de ler. 49. ed. São Paulo: Cortez, 2008.

FUHRMANN, Nadia; PAULO, Fernanda dos Santos. Educação Não Formal no Brasil Hodierno: programa socioeducativo e formação de educadores. Educação \& Sociedade, Campinas, v. 35, n. 127 , s/p, 2014.

GOHN, Maria da Gloria. Educação não formal e cultura política: impactos sobre o associativismo do terceiro setor. 3 ed. São Paulo:Cortez, 200। .

GOHN, Maria da Gloria. Educação não-formal e o educador social: atuação e desenvolvimento de projetos sociais. São Paulo: Cortez, 2010.

HORTON, Myles; FREIRE, Paulo. We make the road by walking: Conversations on education and social change. Philadelphia: Temple University Press, 1990. 
LORD, Lucio. Educação, Política e Periferia: estudo sobre o movimento de educadores populares em Porto Alegre. 20 II. Tese (Doutorado em Ciências Sociais) - Universidade Estadual de Campinas, Campinas, 2011.

LUZURIAGA, Lorenzo. História da Educação e da Pedagogia. São Paulo: Editora Nacional, 1983.

MATUDA, Fernanda Guinoza. Telecentro comunitário como espaço de educação social: um estudo de caso Educação. 2009. Dissertação de-(Mestrado em Educação) - Universidade de São Paulo, São Paulo, 2009.

NATORP, Paul. Pestalozzi, su vida y sus ideas. Traducción de Luis Sánchez Sarto. Colección Labor. Biblioteca de Inicición Cultural. Barcelona-Buenos Aires: Labor S/A, 1931.

NUÑEZ, Violeta. Pedagogía Social: cartas para navegar en el nuevo milenio. Buenos Aires: Santillana, 1999.

NUÑEZ, Violeta. La educación en tiempos de incertidumbre: las apuestas de la Pedagogía Social. Barcelona: Editorial Gedisa, 2002.

PAULO, Fernanda dos Santos. Formação dos/as Educadores/as Populares de Porto Alegre Formados/as em Pedagogia: identidade, trajetória e desafios. 20 I 0. Monografia (Especialização em Educação Popular: Gestão de Movimentos Sociais) - Instituto Superior de Educação Ivoti \& Instituto de Desenvolvimento Brava Gente, Porto Alegre, 2010.

PAULO, Fernanda dos Santos. A Formação do (as) Educadores (as) Populares a partir da Práxis: Um estudo de caso da AEPPA. 20 13. Dissertação (Mestrado em Educação) - Universidade Federal do Rio Grande do Sul, Porto Alegre, 2013.

PAULO, Fernanda dos Santos. Pioneiros e pioneiras da Educação Popular freiriana e a universidade. 20 I8. Tese (Doutorado em Educação) - Universidade do Vale do Rio dos Sinos, São Leopoldo, 2018.

PALUDO, Conceição. Educação popular como resistência e emancipação humana. Cadernos CEDES, Campinas, v. 35, n. 96, p. 219-238, ago. 2015.

RIBAS MACHADO, Érico. O desenvolvimento da Pedagogia Social sob a perspectiva comparada: o estágio atual no Brasil e Espanha. 2014. Tese (Doutorado em Educação), Universidade de São Paulo, São Paulo, 2014.

RIBEIRO, Marlene. Exclusão e educação social: conceitos em superfície e fundo. Educação \& Sociedade, Campinas, v. 27, n. 94, p. I55-178, abr. 2006.

ROUSSEAU, Jean-Jacques. Emílio ou Da educação. 3.ed. Rio de Janeiro: Bertrand Brasil, 1995.

SACRISTÁN, J. Gimeno; GOMÉZ, A. I. Peréz. As funções sociais da escola: da reprodução à reconstrução crítica do conhecimento e da experiência. Compreender e transformar o ensino. Porto Alegre: ARTMED, 2000.

SEVERO, José Leonardo Rolim de Lima. Pedagogia e educação não escolar no Brasil: crítica epistemológica, formativa e profissional. 20I 5. 266 f. Tese (Doutorado em Educação) - Universidade Federal da Paraíba, João Pessoa, 2015. 
SILVA, Roberto da; SOUZA NETO, João Clemente de; MOURA, Rogério Adolfo (org.). Pedagogia social. São Paulo: Expressão e Arte, 2009.

SCHUGURENSKY, Daniel. Social Pedagogy in North America: historical background and current developments. Pedagogía Social. Revista Interuniversitaria, Arizona, 2016, 27, p. 225-25I.

TRILLA, Jaume. La Educacion fuera de la escuela. Ambitos no formales y educación social. Barcelona: Ariel, 1996.

WÜRTH, Tiago. Pestalozzi e a Pedagogia Social. Canoas: Instituto Pestalozzi, 197I.

\section{COMO CITAR ESSE ARTIGO}

\section{Associação Brasileira de Normas Técnicas (ABNT)}

PAULO, Fernanda do Santos; TESSARO, Mônica. Semelhanças e diferenças entre as concepções de educação social, educação popular e educação não escolar. Debates em Educação, Maceió, v. 12, p. 7697, dez. 2020. ISSN 2175-6600. Disponível em:

https://www.seer.ufal.br/index.php/debateseducacao/article/view/90 I5. Acesso em: dd mmm. aaaa.

\section{American Psychological Association (APA)}

Paulo, F., \& Tessaro, M. (2020). Semelhanças e diferenças entre as concepções de educação social, educação popular e educação não escolar. Debates em Educação, 12(Esp2), 76-97. doi: https://doi.org/10.28998/2175-6600.2020v12nEsp2p76-97 